Int. J. Electrochem. Sci., 16 (2021) Article ID: 210656

International Journal of

ELECTROCHEMICAL

SCIENCE

www.electrochemsci.org

\title{
Corrosion Inhibiting Effect of Cetyl Pyridinium Chloride on Aluminium in Acid Media in Presence of KI
}

\author{
P. Muthukrishnan ${ }^{1}$, Ramachandran Rajakumaran ${ }^{2}$, Shen-Ming Chen ${ }^{2, *}$, Tse-Wei Chen ${ }^{2,3}$, \\ T. Pazhanisamy ${ }^{4, *}$, Syang-Peng Rwei ${ }^{3,5}$, Xiaoheng Liu ${ }^{6 *}$,Jaysan $\mathrm{Yu}^{7}$, Richard $\mathrm{Yu}^{7}$ \\ ${ }^{1}$ Department of Chemistry, Faculty of Engineering, Karpagam Academy of Higher Education, \\ Coimbatore-641021, India. \\ ${ }^{2}$ Department of Chemical Engineering and Biotechnology, National Taipei University of Technology, \\ Taipei, Taiwan 106 (ROC). \\ ${ }^{3}$ Research and Development Center for Smart Textile Technology, National Taipei University of \\ Technology, Taipei 106, Taiwan, ROC. \\ ${ }^{4}$ Department of Chemistry, Thanthai Hans Roever College, Perambalur-621220, India. \\ ${ }^{5}$ Institute of Organic and Polymeric Materials, National Taipei University of Technology, Taiwan \\ ${ }^{6}$ Key Laboratory of Education Ministry for Soft Chemistry and Functional Materials, Nanjing \\ University of Science and Technology, Nanjing 210094, China. \\ ${ }^{7}$ Well Fore special wire corporation, 10, Tzu-Chiang 7 rd., Chung-Li Industrial Park, Taoyuan, Taiwan

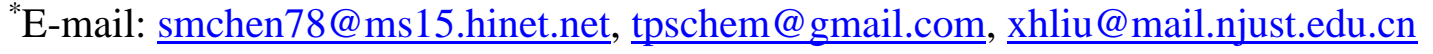

doi: $10.20964 / 2021.06 .20$

Received: 20 January 2021/ Accepted: 24 March 2021 / Published: 30 April 2021

Kalium iodide (KI) used as a synergist in the presence of cetyl pyridinium chloride (CPC) for corrosion inhibition of aluminium in $0.3 \mathrm{M} \mathrm{HCl}$ was evaluated through electrochemical and non-electrochemical techniques. From electrochemical analysis and gravimetric techniques, the efficiency of inhibition enhances with raising the CPC concentrations $\left(3.6 \times 10^{-5}-2.3 \times 10^{-4} \mathrm{M}\right)$ in combination with $6 \times 10^{-4} \mathrm{M} \mathrm{KI}$ and decreases with temperature rise. Curves of polarization suggest that the synergistic formulation behave as a commingled inhibitor, predominately cathodic nature. The addition of $6 \times 10^{-4} \mathrm{M} \mathrm{KI}$ in $0.3 \mathrm{M}$ $\mathrm{HCl}$ with $2.3 \times 10^{-4} \mathrm{~N}$ CPC raises the charge transfer resistance $\left(\mathrm{R}_{\mathrm{ct}}\right)$ and diminishes double layer capacitance $\left(\mathrm{C}_{\mathrm{dl}}\right)$, both are confirmed by electrochemical A.C Impedance analysis. The effect of activation energy, enthalpy and entropy on aluminium corrosion rates was discussed. Langmuir and ElAwady isotherms were checked the adsorption of CPC in the presence of KI. Confirmation of functional groups and formation of protective layer through vibrational spectroscopy study. The obtained results indicate that the KI acts as a good synergist corrosion inhibition of aluminium.

Keywords: Aluminium; Electrochemical, A.C Impedance analysis, Corrosive media; Charge transfer resistance; SEM; EDX 


\section{FULL TEXT}

(C) 2021 The Authors. Published by ESG (www.electrochemsci.org). This article is an open access article distributed under the terms and conditions of the Creative Commons Attribution license (http://creativecommons.org/licenses/by/4.0/). 